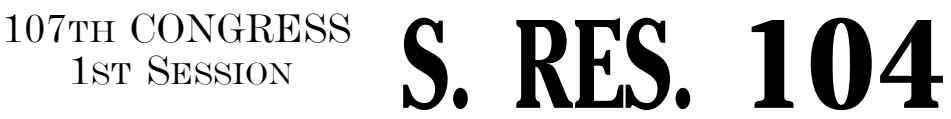

Electing Martin P. Paone as Secretary for the Majority of the Senate.

\section{IN THE SENATE OF THE UNITED STATES}

JUNE 6, 2001

Mr. DASCHLE submitted the following resolution; which was considered and agreed to

\section{RESOLUTION}

Electing Martin P. Paone as Secretary for the Majority of the Senate.

1 Resolved, That Martin P. Paone, of Virginia, be, and

2 he is hereby, elected Secretary for the Majority of the Sen-

3 ate, effective June 6, 2001. 